\title{
Estudios sobre dos textos de Arreola
}

\author{
Studies about Two Arreola's Works \\ Marina Ruano Gutiérrez ${ }^{1}$ \\ Departamento de Letras. Universidad de Guadalajara (MÉXICO) \\ CE: marinaruano@yahoo.com \\ Roberto Herrera Gallardo² \\ Departamento de Letras. Universidad de Guadalajara (MÉXICO) \\ CE: robertoletrashispanicas@gmail.com \\ Eduardo Ortiz Arámbula ${ }^{3}$ \\ Departamento de Letras. Universidad de Guadalajara (MÉXICO) \\ CE: ortizae@yahoo.com \\ Irma Angélica Bañuelos Ávila ${ }^{4}$ \\ Departamento de Letras. Universidad de Guadalajara (MÉXICO) \\ CE: irmaisla@hotmail.com
}

DOI: $\underline{10.32870 / \text { sincronia.axxiv.n77.12a20 }}$

Esta obra está bajo una Licencia Creative Commons Atribución-NoComercial 4.0 Internacional

$\mathrm{BY} \cdot \mathrm{NC}$

Recibido: $12 / 04 / 2019$

Revisado: 07/10/2019

Aprobado: 02/12/2019

\footnotetext{
${ }^{1}$ Profesor-Investigador del Departamento de Letras, Universidad de Guadalajara. Doctorado en Humanidades y Artes por la Universidad Autónoma de Zacatecas.

${ }^{2}$ Profesor-Investigador del Departamento de Letras, Universidad de Guadalajara. Doctorado en Educación por la Universidad Pedagógica Nacional.

${ }^{3}$ Profesor-Investigador del Departamento de Letras, Universidad de Guadalajara. Maestría en Diplomata d'Etudes Approfondis (vertiente hispanoamericana) en la Université Paul Valéry, Montpellier III, Francia.

${ }^{4}$ Profesor-Investigador del Departamento de Letras y Coordinadora del Centro de Investigación y Certificación del Español como Lengua Extranjera y Materna en la Universidad de Guadalajara. Doctorado en Filología Española por la Universidad Autónoma de Barcelona, España.
} 


\section{RESUMEN}

Este trabajo tiene como finalidad analizar la narrativa popular, la jerarquía, la producción de códigos y el enfrentamiento entre lo genérico y lo literario en dos cuentos de Juan José Arreola, titulados: "Corrido" y "Parábola del trueque". Tomando en cuenta que el corrido, que nace de la tradición oral, se convierte en uno de los géneros lírico, épico y narrativo de la cultura popular mexicana. El análisis del cuento toma en cuenta el estudio de los personajes, de la narración de los hechos concretos que ocasionan el conflicto y producen la violencia, y, cuál es la causante del conflicto. También se reflexiona en el presente estudio sobre la historia, las costumbres y el hablar del pueblo: estructura discursiva, los elementos gramaticales y los alcances lingüísticos, filológicos y expresivos del cuento. El análisis se centra además en analizar las partes que componen un corrido como pueden ser: la solicitud para relatar lo acontecido, la precisión de datos, las descripciones, las sentencias moralizantes y la despedida. Asimismo, se consideran el punto de vista del narrador testigo que provee de mayor interés al relato, la temática -tragedias pasionales y la función social que desempeñan los corridos populares. La metodología empleada está basada en cuatro métodos de análisis: La sociocrítica, la estilística, la exégesis y la parodia según Bajtin.

Palabras clave: Narrativa popular. Análisis de textos. Corrido. Parábola del trueque.

\section{ABSTRACT}

The purpose of this text is to analyze the popular narrative, hierarchy, production of codes and collision between the generic and the literary in two of Juan Jose Arreola's short stories entitled: "Corrido" and "Parable of the Barter". It is taken into consideration that corridos, which derive from oral tradition, have become part of the epic, lyric and drama genres of Mexican popular culture. The analysis of this short story encompasses the study of the characters, the narration of concrete facts which lead to the conflict and result in violence, and the source of the conflict. This study also deliberates upon people's history, customs, and way of speaking, that is to say: speech structure, gramatical elements, linguistic, philologic and expressive outreach of the story. The text is also centered in analyzing the different parts of the composition of a corrido, such as: the request to tell what has occurred, precision of the 
information, descriptions, moral sentences and farewell. Additionally, the point of view of the witness narrator is taken into account, since this narrator makes the plot more appealing, as well as the topic (passion tragedies) and the social role of popular corridos. The methodology used hereby is based on four methods of analysis: sociological criticism, stylistics, exegesis and parody according to Bakhtin.

Keywords: Popular Narrative Text analysis. Corrido. Parable of Barter.

\section{Exégesis y modelos fundantes}

En el cuento de Juan José Arreola, titulado "corrido", se narra la historia dos hombres atraídos por la misma muchacha, y por tanto rivales de amor, que el azahar se encarga de reunirlos a los tres en la plaza del pueblo. La muchacha, al enterarse de la presencia de los dos hombres, sale de prisa, tropieza, se rompe el cántaro y se derrama el agua. En la plaza vacía quedan los dos rivales solos dándose muerte uno al otro. A la muchacha del "cántaro quebrado" (Arreola, 1952) se le quedó el "mal nombre de mancornadora" (Arreola, 1952).

En el estudio de la Literatura europea y la Edad Media latina, Curtius presenta las partes que debía incluir la retórica de ese tiempo, que consistían en disposición y transición. La disposición se dividía en: introducción, parte central y conclusión. La transición iba antes de la parte central (Curtius, 1998, pp.97-120). Para este trabajo se han propuesto elementos equivalentes a los utilizados en la retórica medieval.

El cuento "Corrido" se encuentra dividido estructuralmente por los elementos siguientes: ubicación geográfica, descripción del escenario, transiciones, parte central y conclusión.

La ubicación geográfica, en donde se desarrolla el suceso narrado en el cuento, se encuentra expuesta en la plaza llamada de Ameca, situada en la localidad de Zapotlán. La descripción del escenario consiste en la representación de un paisaje desierto y austero, en este panorama sobresale la plaza en la que convergen tres calles. En dicha plaza se encontraba una pileta con una llave de agua, y alrededor de la plaza se encuentran las casas con sus grandes puertas. Las transiciones son todas aquellas aportaciones extras que ofrece el cuento para enriquecer la narración con detalles que 
complementan la descripción principal y que acentúan las características de un paisaje árido y polvoriento transitado por carretas que levantan polvo. La parte central presenta la importancia que juega el destino al permitir el encuentro, de los personajes en discordia, en un mismo lugar y a la misma hora. Cada personaje camina por una calle distinta, cada uno tenía una vida, y finalmente se unen las tres calles en una misma plaza, la unión marca el destino funesto de los personajes que se encuentran de frente con la tragedia: la muerte de los dos hombres y el desprestigio de la muchacha. El solo hecho de la coincidencia, deja ver la razón implícita de una rivalidad existente, la causa consistía en estar ilusionados por la misma muchacha, seguida de la interpretación de las señales, el mensaje de la mirada, descifrada con un diálogo aparente, sin voz, al que recurre el cuento para animar la narración:

-Oiga amigo que me mira

-La vista es muy natural.

Tal parece que así se dijeron (Arreola, 1952).

E inicia una pelea a muerte entre los dos "amigos", alentada, como en los cantos épicos, con la descripción de las armas: una daga y un machete costeño. Y prosigue con los detalles de la pelea: "Y se dieron de cuchillazos, sacándose el golpe un poco con el sarape [...] peleando por los destrozos del cántaro" (Arreola, 1952) como el botín de guerra. En esta épica pelea a muerte suceden acontecimientos extraordinarios, el primer acontecimiento marcado como una intervención divina está representada en el momento en el que la tarde se detiene para dar tiempo a las descripciones de las imágenes de la muerte: “quién degollado y quién con la cabeza partida" (Arreola, 1952), y el segundo acontecimiento extraordinario, al estilo homérico, se encuentra en el momento en que a uno de los personajes le queda un soplo de aliento sólo para preguntar si su rival también había muerto. En la conclusión, finalmente, como la Osa homérica, la noticia se propaga por todas partes y "muchas gentes vinieron" (Arreola, 1952). Y como la Fama virgiliana que "está dotada de numerosas bocas y muchos ojos que nunca sierra, y viaja volando con grandísima rapidez" (Virgilio, 2000, Canto 
IV), esa Fama, que todo lo sabe, va divulgando los rumores, y por doquier se da a conocer que la muchacha "la del cántaro quebrado" (Arreola, 1952) fue la causante de la tragedia.

La peculiaridad del cuento, al carecer de fecha y nombre de los personajes, consiste en llevar implícito el mensaje de que a cualquiera le puede suceder una tragedia similar a la expuesta, esa flexibilidad ha permitido que el cuento "Corrido" fura adaptado para la realización de algunos cortometrajes.

El estilo de este cuento guarda cierta analogía con los romances tradicionales, porque "no expone una serie de sucesos complicada y completa, sino que se limita a desarrollar una escena, una situación, un momento" (Menéndez, 1968, p.63). En la narración emplea un lenguaje popular o "lengua hablada cotidiana" (Gómez, 1984, p.16), que al igual que el romance tradicional, el autor ajusta y amolda a su más natural manera de expresión, agregando su propia sensibilidad e imaginación (Menéndez, 1968, pp.45-49), y conserva ciertas expresiones con características propias del lenguaje hablado como: "Uno con daga, pero así de grande" (Arreola, 1952), frases cortas que expresan todo con pocas palabras. Y el empleo de palabras del habla popular como: ochavada, testerazo, embebidos, tiznada.

\section{Reminiscencia temática}

Los aedas griegos ya cantaban sobre temas amorosos o de desamor, como el tema de la mujer pretendida por dos hombres y con desenlace fatal, "ya en tiempos de Homero, el don oratorio se consideraba cualidad preeminente, regalo de los dioses" (Curtius, 1998, p.99). El ejemplo más característico se halla en la épica homérica representada en Helena, motivo de la caída del reino de Priamo (Homero, 2000).

Durante la Edad Media, los juglares se encargaban de transmitir todo tipo de noticias, incluidas las tragedias pasionales. La tradición de oral perdura con los cantos de los romances, un ejemplo se encuentra en el romance español recogido en el cancionero anónimo del siglo XVI, titulado "La esposa infiel":

\footnotetext{
“¿Quién es este caballero,
} 
que en mi cama veo yo?"

“¡Mátame, marido mío,

que te he jugado traición!" (Anónimo, S. XVI).

Una variación de este romance de "La esposa infiel" se encuentra en el corrido mexicano titulado "La Martina". Respecto al corrido mexicano, Vicente T. Mendoza considera que:

Los conquistadores hispánicos aportaron los usos y costumbres peninsulares a nuestro territorio, donde pasando a través de la sensibilidad aborigen, se transformaron y produjeron nuevos brotes, conteniendo así los dos elementos que los informan: el indígena y el hispánico [...] el corrido mexicano, género completamente popular, constituye uno de esos brotes, es un exponente de la sensibilidad de nuestro pueblo, siendo su antecesor directo, literario y musical, el romance español. (Mendoza, 1997, pp.3-4).

Otros casos sobre la temática de dos hombres atraídos por la misma mujer son los que se encuentran en varios corridos mexicanos, al respecto, Vicente T. Mendoza en su libro titulado Corrido mexicano recopila algunos de ellos, considerados de tragedias pasionales, como el ejemplo siguiente titulado "Los dos hermanos":

_Mira, Juan Luis, que te digo

que esa mujer ya fue mía.

_No tengo la culpa hermano,

eso yo no lo sabía.

[...]

Se salieron para afuera

y se oyeron dos disparos,

y en el quicio de una puerta

los dos hermanos quedaron (Mendoza, 2003, p.332). 
A los corridos que proceden de los romances ibéricos se les conoce como corridos líricos o corridos de origen colonial. Se les denomina también como corridos líricos a los corridos que tratan temas amorosos o pasionales, y que por lo general no contienen pasajes épicos.

En cuanto a la temática del cántaro roto, en el cuento "Corrido" de Juan José Arreola, el cántaro roto simboliza la muerte de los dos hombres y también el desprestigio de la muchacha. "El cántaro roto simboliza la muerte y la pérdida de la virginidad en varias culturas" (Anónimo, 2013). El chorro del agua que se derrama fue la señal para dar inicio a una lucha, y al romperse el cántaro marca el momento fatal de los personajes en el que los dos hombres se dan muerte uno al otro.

La temática del cántaro roto como símbolo de la muerte, ya estaba presente en el libro del Eclesiastés, en el que se representa a la muerte como "el cántaro se quiebra junto a la fuente" (Eclesiastés, 12:6). El mismo sentido del cántaro roto como símbolo de la muerte se encuentra en el poema "El cántaro roto" de Octavio Paz: “¿Todos se han muerto, se han ido, cántaros rotos al borde de la fuente cegada?" (Paz, 1989, p.81).

Mientras que, por otra parte, las coplas y seguidillas populares recogen la simbología poética del cántaro roto como la pérdida de la virginidad, como en el ejemplo siguiente, transcrito por Andujar:

La rosa fue por agua y le dijo el lirio:

deja el cántaro rosa y vente conmigo.

Pobre cantarito mío,

Hoy lo lloro amargamente

Porque ayer me lo rompieron

Caminito de la fuente (Somoza, en Ochoa, 1840, p.765, en Andujar, 2011).

Otra muestra más se encuentra en el romance titulado la "Canción de la sed del agua":

Mi madre bien me decía

que el cántaro no esposiera,

más yo que tan frágil era

el cántaro, no creía (Somoza, en Ochoa, 1840, p.765). 
La temática del cántaro roto también la presenta el autor Lope de Vega, en la comedia titulada $L a$ moza del cántaro, en la que Isabel le dice a Juan:

Isabel.- De buena gana le diera

a ella el agua, y a vos

el cántaro" (Vega, 2018, p.59).

Al igual que la Fama, los aedas, los juglares cantores de romances y los cantores de corridos, funcionan como medios informativos que se encargan de llevar las noticias al pueblo y convencer a través de la palabra.

\section{El “Corrido” de Juan José Arreola como tópico de la cultura popular}

El texto como representación de un tópico recurrente en la cultura y la épica de los pueblos de Jalisco y en su narrativa popular, adquiere desde el cosmopolitismo de Arreola una nueva dimensión en este breve divertimento narrativo denominado simplemente "Corrido".

Arreola apela a un canon más cercano al del pregonero de plaza que igual que anuncia albricias, impreca desgracias, pero lo hace despojado del tono elegiaco, para concentrarse en un vitalismo presente lleno de temperatura, color y vivacidad casi cinematográficas en el que, cuadro a cuadro, se despejan las motivaciones y tensiones que alimentan la acción y la precipitan, logrando el ritmo e incluso la musicalidad precisa que sólo se desarrolla en una prosa llena de lirismo vernáculo.

El pregonero da paso en "Corrido" a la glosa bravía del cortejo instintivo, más que amoroso, de dos machos envalentonados que se atienen a su sola intención de pleito para desencadenar la tragedia en una plaza de pueblo transformada en el redondel de un palenque de furias y veleidades.

En el escarceo, los gallos se encuentran, se reconocen y miden, se tantean en el reducido espacio de su propia intolerancia. Los rivales se saben insoportables, irreconocibles e inconcebibles 
entre sí, cuando la prenda deseada, la hembra del cántaro rojo, derrama e inflama su deseo, su ira y su ineludible afán de reto, pelea, prueba y confrontación.

La representación de la hombría activa y violenta y de la feminidad pasiva y temerosa, tan recurrente en la trova popular mexicana, adquieren en "Corrido" una presencia material y explícita en sus connotaciones sexuales y en el fallido código de la depredación voraz del macho enfrentado a otro rival de igual furor ante la presa, que invisibilizada, pasa un segundo plano, cediendo su calidad de objetivo a la furia de los machos en lucha y su deseo vehemente por demostrar quién es más "hombre", quién es más bravo y por tanto "más merecedor" de la mujer en disputa, que en todo su dramático infortunio ya ha sido reducida a calidad de trofeo. Ante el inminente desenlace que como desgracia cae sobre ella, a la joven espantada no le queda sino huir, correr por su vida, correr derramando el agua, correr haciendo añicos el cántaro y con él su honorabilidad de mujer.

La incorporación de una cinemática súbita e inalterable anuncia y enuncia como en el corrido popular, el destino trágico que habrá de cumplirse para al final anidar en la memoria muda de los testigos circundantes a la arena de las afrentas: las mujeres que rezan asustadas y los hombres que "dan parte" a la autoridad.

La suerte echada se riega como la sangre, apelmazando el polvo de tepetate ("finito, finito") para convertirse en rumor primero, luego en clamor con ápices de leyenda, del que están hechos los días por venir.

La "mala fama" trágica y arteramente injusta de mancornadora, perseguirá como saldo terrible a la joven del cántaro rojo durante todos los días que dure su existencia, cifrándola, estigmatizándola e incriminándola irredenta. De nada le valdrá huir porque su negra fama la perseguirá hasta el último confín del mundo, "hasta Jilotlán de los Dolores", el punto más lejano de la cosmogonía serrana de los pueblos del sur de Jalisco.

Arreola sabe, como juglar de la memoria colectiva, que sólo en los corridos reside la épica de los pueblos, en ellos se concentran las formas más elaboradas de representación de lo propio y de lo ajeno, que al final se agrupa en la identidad, recreándose así misma en el terreno inmaterial del temperamento y la conciencia popular. 


\section{Análisis discursivo}

La intención del presente acercamiento es realizar un breve recuento de los resultados de un análisis discursivo del cuento "Corrido" de Juan José Arreola. Este análisis se centra en el proceso de identificar y organizar patrones y comportamientos reiterativos en el mismo material verbal que constituye al texto. He organizado este material en los siguientes y consecutivos aspectos. El paratexto, el Espacio, Lo femenino y lo Masculino, y Lo Biológico o natural. Sólo para situar un poco este trabajo quiero citar una frase de María Amoretti sobre esta metodología: María Amoretti (1993) señala que "La Sociocrítica es una reflexión materialista sobre la literatura, cuyo objeto consiste en encontrar en el texto artístico los trazados ideológicos que subyacen en él y evidencia existencia de conflicto" (pp.111-112).

1. El paratexto de este cuento de Juan José Arreola presenta como programa fundador la intención de realizar una analogía entre los materiales pertenecientes al género del corrido y el cuento mismo que el paratexto anuncia. Como sabemos el título de un relato nos proporciona una direccionalidad semiótica, una codificación específica que tendremos que utilizar para generar sentido a la hora de realizar la lectura del mismo texto que intitula. En el cuento de Arreola nos encontramos con un comportamiento muy curioso: al mismo tiempo que pretende afiliar al relato con un género, modifica los elementos y su estructuración para ofrecer una variante compleja y novedosa, el paratexto señala que debemos, como lectores y como narratarios, seguir una guía que tal vez no esté necesariamente en el propio relato. El corrido típico es un relato en verso que canta las hazañas de unos héroes o de unos malhechores, de preferencia, para que sea épico, debe proporcionar los mejores datos biográficos de sus protagonistas, sean reales o imaginarios; los datos que el cuento de Arreola nos proporciona distan mucho de resultar así. En el cuento de Arreola, más que hazañas, se nos narra un hecho de sangre, una tragedia propiciada por la violencia, el canto al triunfo de alguno de los protagonistas más bien parece una mirada irónica o sarcástica a ciertas consideraciones morales de nuestra sociedad, al adjudicarle a la muchacha la responsabilidad 
de los hechos y unas consecuencias injustas para su "honra" también. Así pues, la pertenencia a un género específico -el corrido- del cuento de Arreola se encuentra problematizada, pero es precisamente dicha problematización, la que ejecuta una de las muchas eficacias narrativas y literarias del cuento. Arreola utiliza un modelo narrativo e ideológico para hacer otra cosa, para presentarnos una variante discursiva de una enunciación moral hacia lo femenino.

2. El Espacio. A raíz de todas las presencias y reiterados registros que el texto mismo muestra, podemos afirmar que una de las constantes semióticas es la del espacio como una preocupación muy importante. La primera relación importante que el texto lleva a cabo con el espacio es la de la denominación, al espacio se le adjudican un nombre, pero sobre esta denominación se encuentra la presencia de lo incierto, de la incertidumbre. El espacio es también y por supuesto un actante, los espacios fungen como propiciadores de la acción o razón de la misma. Los espacios actúan, son el lugar de la acción, acción y espacio van literalmente de la mano. El espacio es también en nuestro cuento un objeto, o mejor dicho, una serie de objetos, y siguiendo con esta idea, el espacio funge también como una propiedad (ya de un colectivo, ya de un singular, incluso hay objetos que son propiedad de otros objetos). El espacio define la relación que los personajes mantienen con él y que mantienen entre ellos mismos.

3. Lo femenino y lo masculino. Como resulta evidente, otro juego de elementos constantes que actúan en la diexis, en la narración, para dar lugar a funcionamientos muy complejos. La muchacha y los dos rivales que se matan "por ella" se constituyen como entidades sígnicas con sus propios desempeños. Por principio, lo masculino es representado como plural, lo femenino como singular. Tanto los hombres como la mujer se hayan sometidos a padecer las acciones de los objetos o de elementos de la naturaleza. Los objetos y los espacios, pues, son tan protagonistas como las representaciones humanas de los personajes. La muchacha es poseedora de un signo muy importante: un cántaro rojo. Es una propiedad que la caracteriza. Los rivales (hombres) situados en el espacio ignoran el devenir de sus acciones (un golpe en un elemento que funge como espacio y objeto: "el testerazo"). Los tres protagonistas, 
hombres y mujer, se relacionan con los signos de la apariencia ("tal parece que se dijeron sin hablar"), del determinismo ("su destino"), y del espacio de su propiedad ("su calle"). La muchacha mantiene un objetivo muy preciso, el agua, mientras que los dos hombres, descubren su objetivo, motivo, casi al mismo tiempo, la muchacha. La muchacha quiere abrir la llave, los hombres se sienten descubiertos uno por el otro a la vez que descubren a la muchacha; saben lo que quieren. Esta secuencia de acción narrativa marca el fin del espacio, literalmente, para los personajes masculinos, y esto es reforzado por la exposición de una voluntad negativa ("no querer dar un paso adelante", no "no dejar de hacer"). La instancia narrativa indica que la mirada de cada uno de los hombres es una cora, un objeto, casi tirante.

4. Ver - Mirar. En cuanto a la importancia de la sistemática del ver y el mirar, radica en que se constituye como un sistema de comunicación en sí misma. Es un factor de la naturaleza ("la vista es muy natural"), es un cuestionamiento ("oiga, amigo, qué me mira"), y es un sustituto de la palabra ("La mirada lo estaba diciendo todo"). También funciona la mirada, el ver, como una suerte de compromiso, de acuerdo ("embebidos uno y otro en los puntos negro de sus ojos").

5. La naturaleza, la biología. Los factores de la naturaleza resaltan por sus comportamientos textuales. El agua, en este cuento funciona como un signo relacionado con la violencia y el temor; y el enfrentamiento (es el primer motor de la acción, y va llenando el cántaro al mismo tiempo que los corazones de los hombres de ganas de pelar). Cuando el agua se derrama del cántaro de la muchacha, ésta se lo echa al hombro y casi "corre del susto". Al dar "un mal paso", se le cae el cántaro a la muchacha y se rompe en el suelo, Después de la violencia, lo único que permanece en el espacio es la mancha del agua en el piso y los trozos del cántaro. El agua es señal y motivo de violencia. Por otra parte, el cuento lleva a cabo una analogía, una comparación igualadora, entre los hombres y los gallos de pelea. Los protagonistas masculinos son animalizados por la narración, para acentuar sus características violentas e irracionales. Los hombres cambian de motivo para la acción, por medio de la intervención del agua, pasan 
de su interés por la muchacha al interés de aniquilarse el uno al otro, y su fin último es saber si al enemigo "también se lo cargó la tiznada".

\section{La parábola como enseñanza, un análisis del cuento "Parábola del trueque"}

El término parábola posee dos sentidos: Uno como narración de la que se extrae una enseñanza moral; el otro proviene de las matemáticas y describe una curva abierta formada por dos líneas simétricas respecto de un eje en el que todos sus puntos están a la misma distancia de un punto y de la directriz. En este espacio se analiza el cuento desde las dos acepciones; por un lado, bajo el refrán de "no todo lo que relumbra es oro", Juan José Arreola (1971) nos muestra a un hombre que decide no cambiar a su esposa "vieja" por una nueva en un trueque en apariencia ventajoso; sin embargo, lo que debería ser una enseñanza no exenta de moral, y a su vez un comportamiento ejemplar, desde una parodia de lo cristiano se convierte en un infierno de culpa. Es ahí en donde el sentido del cuento recorre una curva cuyas líneas giran en torno a un eje central (la culpa); y a la misma distancia se contrapone un mundo de sentidos verdaderos: lo rubio frente a lo moreno, la luz ante la oscuridad, la felicidad ajena frente al dolor y la verdad contra el engaño.

Al grito de "iCambio esposas viejas por nuevas!" el mercader recorrió las calles del pueblo arrastrando su convoy de pintados carromatos. [Las transacciones fueron muy rápidas, a base de unos precios inexorablemente fijos. Los interesados recibieron pruebas y certificados de garantía, pero nadie pudo escoger. Las mujeres según el comerciante, eran de veinticuatro quilates. Todas rubias y todas circasianas. Y más que rubias, doradas como candeleros (Arreola, 1971, p.117).

Este primer párrafo del cuento la parábola del truque nos sitúa en el vértice de la historia, a la posibilidad de cambiar a una esposa vieja por una nueva, se abren por lo menos dos posibilidades, quedarse con lo antiguo y por tanto conocido o cambiar y encontrar en lo nuevo posibles sorpresas. Arreola fue sin duda un escritor adelantado a su tiempo, porque en su texto encontramos ante una 
parodia posmoderna. La parodia a menudo llamada también cita irónica, apropiación o simplemente intertextualidad -es considerada comúnmente un fenómeno que se halla en el centro del postmodernismo, tanto para los detractores como para los defensores de este último.

Seguramente a Arreola poco le habría importado si su texto sería catalogado como posmoderno, el trataba de hacer una parodia de las parábolas tan usadas en el contexto religioso e ironizar con su particular y única manera sobre temas como la culpa, la fidelidad, las convenciones sociales o el desengaño entre otros.

Yo me quedé temblando detrás de la ventana, al paso de un carro suntuoso. Recostada entre almohadones una mujer que parecía un leopardo me miró deslumbrante, como desde un bloque de topacio. [...] me aparté de la ventana y volví el rostro para mirar a Sofía [...] Ella estaba tranquila, bordando sobre un nuevo mantel las iniciales de costumbre. Ajena al tumulto, ensartó la aguja con sus dedos seguros. Sólo yo que la conozco podía advertir su tenue, imperceptible palidez (Arreola, 1971, pp.117-118).

A través de un doble proceso de instalación e ironización, la parodia señala cómo las representaciones presentes vienen de representaciones pasadas, por ejemplo, la mujer teje en el mantel las iniciales de costumbre y sólo el narrador- personaje advierte en ella cierta inquietud; y las consecuencias ideológicas que se derivan tanto de la continuidad como de las diferencias. En nuestro ejemplo el personaje- narrador no cambia a su esposa vieja por una nueva y cierra los oídos a oportunidad definitiva. Durante la cena no se hablan, pero al final ella le reprocha "¿Por qué no me cambiaste por otra?" él no puede contestarle, pero afirma "y los dos caímos más hondo en el vacío" (Arreola, 1971, p.118). A partir de este momento la vida de los personajes se convierte en un pequeño infierno, que se asume como un destierro de lo socialmente impuesto. El hombre es el único del pueblo que no cambia a su mujer y además inferimos que esta no es rubia como todas las recién adquiridas:

Desde entonces vivimos en una pequeña isla desierta, rodeados por la felicidad tempestuosa. El pueblo parecía un gallinero infestado de pavos reales. Indolentes y voluptuosas, las mujeres permanecían todo el día echadas en la cama. Surgían al atardecer, resplandecientes a los rayos del sol. (Arreola, 1971, p.118). 
Ante la felicidad ajena los protagonistas van recorriendo el camino hacia la infelicidad, van delineando esa curva abierta que aparentemente los separa del eje que en este caso es representado por la dicha de los otros.

Según Linda Hutcheon (1993): “La parodia en el siglo XX ha tenido una amplia gama de formas y propósitos, desde el ridículo ingenioso, pasando por lo festivamente lúdico, hasta lo seriamente respetuoso" (p.188) en el caso de Arreola nos encontramos ante un discurso aparentemente serio pero que juega y ridiculiza, a través de la ironía los conceptos de belleza y felicidad socialmente aceptados:

Yo pasé por tonto a los ojos del vecindario, y perdí los pocos amigos que tenía. Todos pensaron que quise darles una lección poniendo el ejemplo absurdo de la fidelidad. Me pusieron sobrenombres obscenos, y yo acabé por sentirme como una especie de eunuco en aquel edén placentero. (Arreola, 1971, p.118).

Los lectores sabemos que el personaje nunca se plantea aleccionar moralmente a sus vecinos por lo que la parábola se convierte en una falsa parábola, porque no conlleva consigo ningún ejemplo moralizante e incluso el comportamiento de la mujer es también opuesto al esperado por el protagonista:

Sofía se volvió cada vez más silenciosa y retraída...y lo que es peor, cumplía de mala gana con sus más estrictos deberes de casada. A decir verdad los dos nos sentíamos apenados de unos amores tan modestamente conyugales [...] Su aire de culpabilidad era lo que más me ofendía. Se sintió responsable de que yo no tuviera una mujer como las otras...era incapaz de apartar la imagen de la tentación que yo llevaba en la cabeza. Ante la hermosura invasora, se batió en retirada hasta los últimos rincones del mudo resentimiento. (Arreola, 1971, p.119).

La culpa y el resentimiento harán mella en una relación que según los valores cristianos debería haberse afianzado con la demostración de fidelidad del marido hacia la mujer, pero esto no sucede, sino que nos encontramos con el reverso de lo esperado, una parábola negativa según las 
matemáticas. La pena, la culpa y el resentimiento aparecen como antítesis de la aparente lección o enseñanza que los personajes deberían asumir en el texto: “iNo me tengas lástima! / ¡Nunca te perdonaré que no me hayas cambiado!" (Arreola, 1971, p.119). Le recrimina la mujer.

Pero un día las rubias comenzaron a oxidarse... deslumbrados a primera vista, los hombres no pusieron realmente atención en las mujeres.

Lejos de ser nuevas, eran de segunda, de tercera, de sabe Dios cuántas manos [...] El mercader les hizo sencillamente algunas reparaciones indispensables, y les dio un baño de oro tan bajo y tan delgado, que no resistió las pruebas de las primeras Iluvias (Arreola, 1971, p.119).

La parodia dice Linda Hutcheon (1993) no hace caso omiso del contexto de las representaciones pasadas que ella cita, sino que usa la ironía para reconocer el hecho de que estamos inevitablemente separados -hoy día- por el tiempo y por subsiguiente la historia de las representaciones (en este caso las antiguas parábolas cristianas). Si analizamos la parábola desde el punto de vista de las matemáticas esta describe una curva abierta formada por dos líneas simétricas respecto de un eje en el que todos sus puntos están a la misma distancia de un punto y de la directriz. Así pues, irónicamente todas las mujeres eran viejas, usadas, como la parábola todas estaban a la misma distancia y sólo el engaño, el baño de falso oro las alejaba aparentemente del eje, pero todas eran rubias y doradas, es decir eran una especie de réplica unas de otras. También como se ha dicho al inicio ese eje mostrará cómo la culpa aparece como punto de partida del ejemplo moralizante: irónicamente no es el hombre el que se siente culpable por no haber cambiado a la mujer sino es ella la que piensa que su marido no tiene una mujer más bella por su culpa, por la compasión que éste tuvo al no hacer el trueque.

Pero el tercero, que era farmacéutico, advirtió un día entre el aroma de su mujer la característica emanación del sulfato de cobre. Bajo el refrán de no todo lo que relumbra es oro, las mujeres 'enseñan el cobre' ante la indignación de los hombres que incluso se habían arruinado por su compra (Arreola, 1971, p.120). 
Poco a poco salió a relucir la verdad, y cada quien supo que había recibido una mujer falsificada. Es claro que en la historia hay una línea moralizante, que hay un continuo con la parábola tradicional pero también una diferencia irónica, diferencia inducida por la misma historia en donde no solo no hay ninguna resolución de contradicciones, sino que hay una puesta en primer plano de esas mismas contradicciones (el esposo que no cambia a su mujer y la mujer que no es cambiada no son felices, e incluso existe en ellos un distanciamiento originado por el "no trueque, ella no lo entiende como un gesto de fidelidad sino de cobardía, de compasión.

Sofía y yo nos encontramos a merced de la envidia y del odio...pero a Sofía le costaba trabajo disimular su júbilo, y dio en salir a la calle con sus mejores atavíos, haciendo gala entre tanta desolación. Lejos de atribuir algún mérito a mi conducta, Sofía pensaba naturalmente que yo me había quedado con ella por cobarde, pero que no me quedaron ganas de cambiarla (Arreola, 1971, p.121).

En este punto se abre la parábola y cada uno parece encontrarse en puntos equidistantes, donde la recuperación del estado anterior al truque resulta imposible porque el camino recorrido entre los personajes estará separado por líneas equidistantes que jamás podrán volver a juntarse, a pesar de la aparente resolución a su favor.

“Hoy salió del pueblo la expedición de los maridos engañados, que van en busca del mercader [...] las mujeres iban de luto, lacias y desgreñadas, como plañideras leprosas" (Arreola, 1971, p.121). Quizás sean estas líneas donde se podría encontrar cierta enseñanza, estas mujeres al principio amadas (rubias y glamurosas) son denostadas (ahora van de luto -la oscuridad frente a la luz) y desgreñadas (la belleza frente a la fealdad). El gozo inicial de los hombres se ha convertido en ira y en deseo de venganza ante el engaño.

Recuérdese la variedad de textos parodiados, por ejemplo: El nombre de la rosa, de Eco, o la obra de Borges y el mismo Arreola donde la ironía convierte esas referencias intertextuales en algo más que un mero juego intelectual o en cierto retorno infinito a la textualidad. 
"Yo no sé la vida que me aguarda al lado de una Sofía quién sabe si necia o si prudente [...] Ahora estamos en una isla verdadera, rodeada de soledad por todas partes" (Arreola, 1971, p.121). De manera irónica la soledad se impone cuando el conflicto parece resuelto, cuando las mujeres falsificadas son descubiertas, hecho que debería brindar a la pareja una felicidad por lo menos vengativa.

La parodia posmoderna plantea Hutcheon, “es una especie de 'revisión impugnadora' o de relectura del pasado que confirma y subvierte el poder de las representaciones de la historia" (1993, p.193):

Sofía no es tan morena como parece. A la luz de la lámpara, su rostro dormido se va llenando de reflejos. Como si del sueño le salieran leves, dorados pensamientos de orgullo. De manera sorprendente Sofía empieza a convertirse en una mujer rubia, quizás digo yo, no tan diferente de las otras. (Arreola, 1971, p.121).

Toda parodia tiene un cierto potencial deconstructivo y de ello nos da cuenta el narrador-personaje en la cita anterior, en esa apropiación casi subversiva de los valores antes menospreciados, la mujer morena se vuelve rubia a partir del orgullo.

\section{Referencias}

Amoretti, M. (1993). Diccionario de Términos Asociados en Teoría Sociocrítica, San José: Universidad de Costa Rica.

Andujar. (S/f). IDEAL, Recuperado de //andujar.ideal.es/andujar/noticias/201207/18/cantaros-ybotijos.html

Anónimo. (S. XVI). Romancero y cancionero anónimo hasta el siglo XVI. Romances y canciones, http://amediavoz.com/romancero.htm (Obtenido en noviembre de 2015).

Anónimo. (2013). Mis experiencias, mis imágenes, España, en https://drosammisexperiencias.blogspot.com/2013/08/en-la-alfareria-se-llama-cantaro-la.html (Obtenido el 15 de octubre de 2018).

Arreola, J. J. (1971). Confabulario, México: Joaquín Mortíz. 
Arreola, J. J. (1952). “Corrido”, en Luis López Nieves, https://ciudadseva.com/texto/corrido/ (Obtenido el 17 de octubre de 2018).

Curtius, E. R. (1998). Literatura europea y Edad Media latina, México: Fondo de Cultura Mexicana, Sección de Lengua y estudios literarios.

Gómez, P. (1984). El lenguaje y las diferencias sociales, México: EDUG/Universidad de Guadalajara, Cuadernos universitarios, Núm. 2. Segunda Serie.

Homero. (2000). La lliada, Introducción y notas de Juan Alarcón Benito, España: EDIMAT Libros, Ediciones y distribuciones Mateos, Col. Obras Selectas.

Hutcheon, L. (1993). "La política en la parodia posmoderna" en Criterios. Edición especial en homenaje a Bajtin, La Habana, (pp.187-203). Recuperado de http://www.mnba.gob.cl/617/articles-8672_archivo_04.pdf.

Menéndez, R. (1968). Romancero hispánico (hispano-portugués, americano y sefardí, teoría e historia, Tomo l: con ilustraciones musicales de Gonzalo Menéndez-Pidal, Madrid: EspasaCalpe, S.A.

Mendoza, V. T. (1997). El romance español y el corrido mexicano. Estudio comparativo, México: UNAM.

Mendoza, V. T. (Comp.). (2003). El corrido mexicano, México: Fondo de Cultura Económica, Colección popular.

Ochoa, E. (2011). "Canción de la sed de agua, por José Somoza”, en Apuntes para una Biblioteca de escritores españoles contemporáneos en prosa y verso, [Versión digitalizada] París: Bandry. Lib. Europea. Recuperado de https://books.google.es/books?id=RsLZfB3S8UC\&pg=PA765\&dq=c\%C3\%A1ntaro+de+novia\&hl=es\&sa $=X \& e i=H W-$

OT_CRHYfS0QXljqX5DA\#v=onepage \&q=c\%C3\%A1ntaro\%20de\%20novia\&f=false.

Paz, O. (1989). Lo mejor de Octavio Paz. El fuego de cada día, Mexico: Grupo Editorial Planeta, S.A. de C.V.

Vega, F. L. (2018). La moza del cántaro, Barcelona: Red ediciones S.L.

Virgilio. (2000). La Eneida, México: Editores mexicanos unidos. 